\title{
EL TIEMPO DEL DISCURSO JURÍDICO Y EL RELATO PRESCRIPTIVO. NOMOS HISTÓRICOS Y NOMOS PROCESALES
}

\author{
TIME OF LEGAL DISCOURSE AND PRESCRIPTIVE \\ STORYTELLING. \\ HISTORICAL NOMOS AND PROCEDURAL NOMOS
}

\author{
Paulo Damián ANICETO \\ Universidad Nacional de Córdoba-CONICET (Argentina) \\ paulodamiananiceto@gmail.com
}

\begin{abstract}
Resumen: Este ensayo informa del estado de los debates en el campo de la Semiótica Jurídica sobre dos temas: el carácter narrativo de la práctica característica del discurso jurídico, dirigido a la adjudicación del juez, la sentencia; y la función argumentativa que aparece en el horizonte de ese carácter narrativo. Reconocemos detrás de estos temas un problema común sobre el que la semiótica debe detenerse: las operaciones estratégicas que las adjudicaciones enmascaran reenvían a regímenes narrativos donde se sancionan normas sobre el deber ser de las historias relatadas y sobre el campo discursivo donde los relatos emergen.
\end{abstract}

Palabras claves: Apuesta argumentativa. Narración judicial. Nomos histórico. Nomos jurídico.

Abstract: This paper exposes current debates in the field of Legal Semiotics 
about two topics: the narrative nature of the practice of social discourse, oriented to adjudication, and the argumentative function that appears on the horizon of this narrative nature. We recognize one common problem behind these topics, and believe that Semiotics must pay attention: the strategic operations that the adjudications conceal remit to narrative regimes where rules are prescribed on normative ideal of story told and the discursive field where storytellings emerge.

Key Words: Argumentative bets. Judicial narration. Historical nomos. Legal nomos.

La misma imposición de una fuerza normativa sobre un estado de cosas es el acto de creación narrativa [...]. Las narraciones son modelos a través de los cuales estudiamos y experimentamos las transformaciones que ocurren cuando se hace pasar un cierto estado de cosas a través del campo de fuerza de un conjunto de normas (Robert Cover, 2002: 76)

\section{INTRODUCCIÓN}

Desde la filosofía política de la práctica jurídica, Ronald Dworkin elaboró una perspectiva crítica del positivismo hartiano que entiende el derecho como un enfoque antes que como un producto acabado. Aquí sintetizamos uno de los elementos de su propuesta y extraemos un aspecto 
para problematizar desde la sociosemiótica landowskiana.

En Law's Empire, Dworkin (1985) desarrolla su perspectiva de la que llama escritura integralista. Desde esta perspectiva, los actores del campo judicial que arriban a una decisión deben atravesar un recorrido de interpretación de la historia de la práctica legal de su comunidad tal como lo haría uno de los autores de una imaginaria novela en cadena. Desde este enfoque, el discurso de jurisdicción de un juez es análogo al de uno de los autores de una novela en desarrollo. Un esquema global de sus creencias y actitudes determina la prescripción de lo jurídicamente preferible en cuanto a la mejor interpretación de la historia de la práctica legal de su comunidad. A esto hace referencia Dworkin (1986) cuando asegura que "una vez que te resuelvas, creerás que la interpretación correcta [...] es la interpretación que mejora la novela en su totalidad" (234).

Aquí aislamos la categoría chain novel del planteamiento general de Dworkin (1985) y la ligamos a una comprensión semiótica de los relatos emergentes en la práctica judicial. Dworkin (1985) se pregunta sobre la relación de determinación entre el pasado del derecho de la comunidad y el presente de la reescritura interpretativa. La característica que envuelve su obra es que, al preguntárselo, convierte tanto la pregunta como la reescritura en parte de la historia incompleta que interpreta.

En el campo jurídico, el dilema se cierne sobre el debate normativo en torno a la discrecionalidad del juez que decide y las restricciones que la norma escrita y las decisiones anteriores (desde el pasado) le imponen.

Nosotros eludimos ese debate, pero reconocemos un tema que reconocemos insinuado por la perspectiva integralista: la imbricación que se produce en el campo discursivo judicial entre el tiempo de lo enunciado y el tiempo de la enunciación.

Prestar atención a esta imbricación implica retirarla del debate teórico entre dominio de la historia magistra vitae vs. horizonte de expectativa de justicia. Asignamos en el integralismo dworkineano una indagación sobre las temporalidades de la práctica discursiva procesal, capaz de nutrir el desarrollo de una visión crítica sobre la semiosis jurídica. 
La totalidad de nuestro planteamiento se apoya en el supuesto de que "discurso jurídico" es la denominación de una práctica estratégica que construye un sujeto con pretensión de corrección jurídica. Asumimos la distinción metodológica establecida por Beatriz Bixio (2016) en su reflexión sobre la tarea de la Semiótica Jurídica:

En algunos casos, el discurso jurídico se separa del discurso legal en un afán de diferenciar el discurso de la elaboración de la ley, como lenguaje primario, y el discurso de la reflexión sobre la ley (los juristas) o de los usuarios de esa ley en el proceso de aplicación de la ley y administrar justicia (abogados, fiscales, jueces, etc.). En otros casos, la mayoría, estos términos se homologan. En nuestro caso esta distinción no es operativa porque tanto el discurso de la ley como de las lecturas que se puedan hacer sobre ella (doctrinaria o con fines prácticos) constituyen un todo inalienable (Bixio, 2016: 241-242).

En otras palabras, abordar el discurso jurídico implica comprender los relatos judiciales por su subsunción a una estrategia de argumentación común. La narrativa del discurso jurídico forma parte de un dispositivo de referenciación de lo justo, de un universo referencial que hemos llamado ámbitos de justicia ${ }^{1}$.

\section{LA SEMIOSIS NARRATIVA DEL CAMPO DISCURSIVO JUDICIAL}

Nuestra reflexión no identifica un actor racional que opta por la que cree la mejor decisión con base en una teoría preexistente.

La mirada sobre las temporalidades del campo discursivo judicial pone a la narratividad bajo un enfoque que desborda la inmanencia de los

\footnotetext{
${ }^{1}$ Véase Aniceto (2017c).
} 
textos legales. Antes bien, entiende que el medio de interacción discursiva es el lugar de una disputa entre sujetos de enunciación que normalizan determinadas representaciones del pasado, al tiempo que categorizan y recategorizan el campo discursivo donde aparecen. Entonces, es una mirada que advierte la necesidad de pensar en la construcción de sujetos, dominios de memoria y campos discursivos.

La palabra judicial es una ruptura que reorganiza el campo discursivo donde aparece. Pone en marcha un proceso de retomes y abandonos, encorsetamientos y desbordes, al cabo del cual la diferencia del acontecimiento judicial termina absorbida por la regularidad de un sistema formal de reparto de sentidos.

Pensar en este punto de dislocación sugiere pensar en el fenómeno complejo de la intersección de temporalidades en el campo discursivo judicial. Buena parte de la teoría crítica elude hacerlo. La relación a la que nos referimos es una que se entabla en la práctica ritual misma de un juicio entre los hechos construidos y el sujeto de jurisdicción. El foco de José Calvo González, por caso, no sustrae el tema a esa zona periférica. El autor es guiado por su original concepción inmanentista de la semiótica, que él deriva de la tradición estructuralista greimasiana de la escuela francesa. El jurista español insiste en diferenciar su posición de la correspondentista ${ }^{2} \mathrm{y}$, en esa dirección, se aboca a tratar el tema de los estándares de coherencia de la estructura narrativa y da por supuesto que los hechos justiciables se configuran en "imágenes mentales vehiculizadas en el soporte de los signos lingüísticos” (Calvo González, 1996: 6).

La semiótica contemporánea parece haber abandonado la idea saussureana a la que remite la categoría imágenes mentales. Según este, habría un significado depositado en la mente del hablante, el concepto, contraído necesariamente con el significante.

Al invocar un test de coherencia narrativa, el autor postula la narratividad del derecho como un objeto de la semántica de la lengua. Y

\footnotetext{
${ }^{2}$ Que sostiene la necesidad, y por lo tanto la posibilidad, de establecer la verdad jurídica como reproducción de la verdad del hecho histórico justiciable.
} 
así, termina sosteniendo la tesis benvenisteana, superada, que entiende los actos de enunciación como la puesta en funcionamiento de la lengua por medio de sistemas interpretantes de todos los demás sistemas de signos, como el jurídico normativo, del cual el hombre se apropiaría.

Los actos de enunciación del discurso judicial producen representaciones judiciales sobre determinados hechos fijados como objeto procesal. Ahora bien, entonces, si de esas representaciones debemos remontarnos a los actos de enunciación, ¿a qué momento deberíamos remontarnos para comprender la naturaleza de los actos de enunciación? La teoría de la discursividad social, a la que nos adscribimos aquí, asegura que tanto los hechos históricos que el discurso judicial reconstruye como la reconstrucción misma emergen en el tiempo histórico. Son hechos, y entre ellos se establecen relaciones contingentes y polémicas.

\subsection{La narración de los hechos justiciables y la narración del juicio de los hechos}

El VII Congreso Internacional Narrative matters. Récit et savoir, en la Universidad Paris Diderot, tuvo, en 2014, una agenda de debate sobre tópicos generales, como el poder de la narrativa ${ }^{3}$, y más específicos, como la relación comúnmente entendida como excluyente entre lo narrativo y lo argumentativo. Entre las preguntas disparadoras anunciadas en su programa figura la siguiente: ¿cómo vehiculiza o produce saberes el relato, y qué saberes vehiculiza y produce? Este interrogante entraña una adhesión a la tesis que afirma que el acto de enunciación del relato

${ }^{3}$ Es de especial interés el artículo La possibilité d'une sociologie narrative, de JeanFrançois Laé, Annick Madec y Numa Murard. Los autores llevan el enfoque foucaultiano a un terreno polémico con el mismo enfoque, donde la sociología es considerada una novela, y una novela, una sociología. A nuestro parecer, si el sociólogo o el juez ostentan poder en la verbalización de los relatos de "lo real" es exclusivamente debido a que están legitimados por un régimen de verdad que los autoriza a instituir ese real mientras lo pronuncian. Por el contrario, sostenemos que el relato del acontecimiento en un juicio es un acontecimiento igual de real al que sigue el de los efectos producidos en la exterioridad del relato. 
comprende un fenómeno circular que se desliza entre la construcción, el autoextrañamiento y la legitimación de lo construido.

Entonces, ¿qué supone el planteamiento sugerido en el interrogante de París para el estudio crítico de la discursividad jurídica?

Detrás de nuestra pregunta asoma un nuevo objetivo: exhumar las estrategias narrativas de justificación que vinculan de maneras singulares el tiempo de lo relatado con el tiempo de los relatos. Nuestra hipótesis, que llamamos de la unidad de veridicción es la siguiente: los enunciados judiciales normalizan sus representaciones del pasado y prescriben lo que aquí denominamos nomos históricos, al mismo tiempo que hacen regir estas normas para sus representaciones del presente judicial, sedimentadas en aquello que llamamos nomos jurídicos.

\subsubsection{Las relaciones de fuerza constitutivas del campo discursivo judicial}

Desde la teoría crítica de la discursividad jurídica abordamos los enunciados procesales en tanto superficie de posicionamientos relacionales: ¿qué papel desempeña el acto de enunciación en el juego de posiciones del propio campo? ¿Cómo normalizan en sus relatos determinados modelos de “el hecho justiciable”? ¿Cómo modelan, en los mismos relatos, las representaciones de lo justo y la justicia como expectativa? ¿Cómo tejen alianzas y adversidades y regulan el espacio lingüístico? Estas preguntas ocupan un lugar central en la tradición semiótica que declaramos como nuestra sede y que reconocemos sugerida en los trabajos de Eric Landowski (1993), Robert Cover (2002), John Frow (1995), Jack Balkin (1991), Enrique Marí (1982), Enrique Kozicki (2004), Boaventura De Sousa Santos (2009), Lucía Asseff (2003) y Susana Frutos (2007). La estrategia analítica común responde a una concepción del campo judicial: la categorización y recategorización (Narvaja de Arnoux, 2009) del pasado mantiene con la categorización y recategorización del campo presente una relación de reenvíos recíprocos. 
La dinámica del campo discursivo judicial debe definirse, por lo tanto, en base a una nunca completa y siempre compleja relación entre: A) el tiempo de lo relatado, analizable en la gramática inmanente a los textos, y B) el tiempo del relato, que podemos iluminar si reconocemos en el discurso las huellas de sus condiciones de producción. Desde esta perspectiva, el origen de lo justo emana de la regularidad de la práctica que lo reconstruye.

\subsubsection{La institución del nomos histórico}

Los argumentos verbalizados en un juicio penal no son abordables desde la Semiótica Jurídica si no identificamos su registro polémico en relación con otros posicionamientos del campo. Llevando esto al terreno de la construcción discursiva del pasado en los juicios, las estrategias de fijación procesal del hecho no son sino relativas. Desde la semiótica narrativista, Jean-François Bordron y Denis Bertrand (en Bertrand, 2015) lo exponen con claridad: "la narratología integra el entorno pragmático de los sistemas semióticos en su realización en discurso" (Bertrand, 2015: 173-174). Si en el ámbito jurídico lo que cuenta es lo que se cuenta, es porque las palabras que convierten a la ley en un acto performativo (Aniceto, 2017b) emergen en el marco de una apuesta por instituir un pasado y un relato normativos.

El discurso jurídico ejerce un poder instituyente en la traducción del storytelling a la discursividad del derecho. Por lo tanto, el objeto de un estudio del relato judicial no se constituye en la sucesión canónica de acontecimientos. Se asigna en las huellas de la unidad de veridicción por una mirada que, al final, concluye que todo discurso reconocido por su juridicidad (Landowski, 1993) aparece condicionado por una matriz argumentativa, que opera como una de sus gramáticas de producción. Esto es tan cierto como el hecho de que el discurso jurídico instituye, a la vez, una transformación de esa matriz.

El deber ser del discurso jurídico, dramatizar la ley como modo 
de hacerla exisitr (Kozicki, 2004), se realiza, en parte, cuando establece singulares, y no declaradas, normas en el horizonte de los relatos. Aquí categorizamos estas normas nomos históricos.

El discurso jurídico designa una apuesta normativa, la de instituir nomos históricos. Es una apuesta, por un lado, por instituir el hecho relatado como el objeto procesal y, por el otro, por subsumir el campo judicial que el discurso mismo categoriza a una norma que prescribe el campo discursivo válido. Relata, pero al hacerlo instituye las condiciones de validez del relato.

\subsubsection{Lo instituido por el sujeto del derecho: la autojustificación}

Enrique Marí (2009) ha desarrollado sin ingenuidad una concepción sobre el poder instituyente del discurso jurídico. Evocarlo implica, entre otras cosas, advertir lo que el mismo Marí (2001), en otro texto ${ }^{4}$, y Calvo González (1996) habían advertido sobre las prescripciones que el discurso jurídico impone a su devenir. Los enunciados del derecho interpretan la historia de la práctica legal, pero, en el tiempo del rito, también controlan, su à-venir (Derrida, 1992), las derivas interpretativas del fragmento de la novela enunciada.

Luis XIV exclamó L'État c'est moi. Flaubert cerraba el dilema producido en torno a la persona aludida por el personaje de Madame Bovary: Madame Bovary c'est moi. Enrique Marí (2001) explora El Banquete de Platón como el soporte de una historia del amor que opera como dispositivo de control de todas las historias de amor. Jean-Marie Le Pen, en agosto de 2015, respondía a una entrevista periodística sobre su exclusión del Frente Nacional por su hija, Marine Lepen: le Front National c'est moi. Mauricio Macri, el actual Presidente argentino, durante el tramo final de su campaña electoral en 2015, anunciaba: "no creemos que el futuro de la Argentina sean recetas del pasado". En aquel momento, gobernaba Cristina Kirchner. El enunciado no-dicho aparece a la vista: "la

${ }^{4}$ El Banquete de Platón: el eros, el vino, los discursos. 
Argentina es aquello que seremos nosotros". El sujeto común a enunciados establece una norma de interpretación del tiempo de la ley, del antes y el después: "la Ley que existe, su historia y su futuro, soy yo".

La economía de la constelación de textos legales no interfiere entre lo justo y el sujeto de discurso, sino que posibilita una versión inédita de aquello en el ejercicio de la práctica narrativa. La enigmática propiedad del discurso jurídico, como asegura Kozicki (2004), descansa en el fenómeno de la producción de sujetos. Lucas Guardia (2013), en sintonía, asegura que:

no puede obviarse, dentro del análisis que implican las condiciones de posibilidad del discurso jurídico, la producción del sujeto - sujeto habitante de un especifico continente de poder [...] - como tampoco los regímenes de verdad que éste consolida a través de su manifestación (Guardia, 2013: 50).

El campo jurídico modeliza tanto un sujeto de enunciación de la ley como una historia por relatar. El sujeto que aparece como tercero equidistante no justifica el razonamiento justificatorio comprendido en su relato sino la decisión a la que arriba. Entonces, el paso del momento instituyente a la consolidación de lo instituido es naturalizado. La marcha de la práctica jurídica sigue las huellas de una mitología inmotivada, la del Pontífice que lleva las leyes en su pecho (Legendre, 1982).

Un enunciador instituye la ley y controla sus derivas interpretativas mediante la autorreferencia. $\mathrm{Si}$, en un primer momento, la ley se instituye como lo otro a describir objetivamente, en un segundo momento, un yo aparece como la encarnación del otro objetivado. Así, la trayectoria del péndulo va de la objetivación a la subjetivación.

Los sentidos invertidos sobre las normas pueden ser reconstruidos por la semiótica si esta reconoce allí un compromiso subjetivo: 
Algunas interpretaciones son escritas con sangre y corren con una garantía de sangre como parte de su fuerza de validación. [...] Esa objetivación implica narrativas que cualquier grupo particular asocia con el derecho y que proveen recursos para la justificación, la condena, y el argumento por actores del grupo que deben luchar para vivir su ley (Cover, 2002: 45-46).

2.1.4. Categorización y recategorizacion del campo discursivo judicial

Nuestro interés, como se desprende de lo dicho, se inscribe en la sede de la teoría de la discursividad social (Verón, 1987, 2013; de Ípola, 2005), y sugiere describir el proceso social de producción del discurso jurídico ${ }^{5}$. El problema que delimitamos en este terreno está en las estrategias de categorización del campo discursivo por los relatos emergentes. Para delimitarlo, nos permitimos anticipar el marco teórico en el que lo consideramos.

La lingüística estructural privilegia el estudio de las relaciones - reglamentarias, gramaticales - entre unidades textuales (análisis proposicional) antes que el texto como materialidad pasible de investirse de sentido como superficie de formaciones discursivas. Detecta referentes explícitos y recursos de su mantenimiento en el texto. Sin embargo, como nos recuerda Verón (2013), "la lengua ya para Saussure era un objeto construido" (71). El estructuralismo de comienzos del siglo XX, que ejerció una importante influencia en el conjunto de las ciencias sociales, postula la construcción de un orden temporal, constituido en la sucesión de los hechos "evocados" en el discurso (Todorov y Ducrot, 2014). Desde esta perspectiva, dicho orden sería fácilmente reconocible en crónicas y relatos, y estaría ausente en discursos no referenciales y descriptivos.

Aquí, en cambio, asumimos esas relaciones asignadas a los textos

${ }^{5}$ En otra ocasión (Aniceto, 2016), hemos descrito esquemáticamente ese campo de interés, el de la Semiótica Jurídica (SJ). 
legales como la contracara jurídica de relaciones estratégicas. El pasado reconstruido en el relato judicial irrumpe vinculado con un sujeto de enunciación que asume un posicionamiento estratégico.

Los enunciadores argumentan, siguiendo a Alexy (2011), su inserción "en un modo de socialización vinculado a normas con la necesidad de justificación" (217). Presentan el tramo de la novela en cadena que pronuncian como lo asignado desde siempre como su parte en un guion.

Aquí asoma un principio de método: los objetos y sujetos reconocibles en los enunciados del derecho (norma y hecho) no son datos a priori en el proceso de sentido (Verón, 1987), sino articulados sobre los enunciados mismos.

Es decir, asistir a un conjunto regular de representaciones sobre la norma y los hechos subsumidos a ella no debe llevarnos a aceptar sin más el postulado normativista según el cual existiría un método certero de juridificación de la experiencia. El análisis del rito procesal no descubre el interior de un método de juridificación, sino que reconstruye el exterior constitutivo de un régimen de representación de la experiencia.

Eric Landowski $(1993 ; 1980)$ menciona un conjunto de categorías que la Semiótica Jurídica toma del repertorio de categorías de la ciencia jurídica y reformula. La convergencia entre el vocabulario del derecho formal y el compuesto por la Semiótica Jurídica landowskiana (en categorías como contrato, objeto, acto, sanción, carga de la prueba) no representa una simple sustitución terminológica. Se propone, más bien, superponer un nivel estratégico al nivel jurídico de comprensión del acontecimiento jurídico. Esto es debido a que el texto legal constituye un fenotexto (Kristeva, 1981): no solo es un hecho lingüístico sino también una práctica significante que hace efectiva una manera específica, entre infinitas maneras posibles, de representación del deber ser. Un texto legal es un conjunto significante plural y contingente.

En síntesis, la estructura de inteligibilidad de la que el sistema jurídico formal ha dotado a sus conjuntos significantes contingentes (el texto y la escena judicial) no obliga a los estudios críticos de la Semiótica Jurídica a darla como venida de suyo. 


\subsection{La prescripción y el tiempo del discurso jurídico}

En Crítica de la ideología jurídica. Ensayo sociosemiológico, Óscar Correas (2005) sostiene un presupuesto básico: la autorización autoatribuida por el yo-enunciador "puede hacer de cualquier enunciado una prescripción" (Correas, 2005: 61).

Entonces, el tipo específico de relación que el lingüista se aboca a describir constituye en una prescripción, una contingencia que determina, no un orden temporal, sino una temporalidad compleja y dinámica. Instituye una determinada referencia a las cosas del mundo:

nos encontramos ante un enunciado de carácter religioso [...] que se impone de manera absoluta e intemporal a todos. El lugar común reiterado hasta el hartazgo sobre el atraso del Derecho con respecto a los hechos desconoce esa temporalidad propia de los sistemas jurídicos (Supiot, 2012: 20-21).

La temporalidad de lo representado en el discurso del derecho se superpone al tiempo de la representación, que emerge al calor de las disputas entre memorias con pretensión de corrección jurídica. Cada actor, en palabras de Perelman y Olbrechs-Tyteca (1989), sostendrá “que su interpretación no la modifica [a la ley], que corresponde mejor a la intención del legislador (179)" (la aclaración es mía), que su discurso inscribe la palabra justa o fata $^{6}$ (Legendre, 2008).

\subsection{1. "Semèia", la inscripción del tiempo judicial}

El teckmerion, "el arte del descubrimiento que utiliza signos, huellas, marcas" (Foucault, 2014: 87) aparece como una característica operativa en

\footnotetext{
${ }^{6}$ Legendre (2008) asegura que fata designaba en la Roma Antigua la referencia a la palabra del destino, la palabra justa.
} 
las obras de la tragedia griega. Es aquel movimiento emprendido desde el presente al pasado, de la presencia del rito a la ausencia del acontecimiento para volver a la presencia del rito. Tanto las pruebas como los indicios de un juicio constituyen prácticas interpretativas mediante las cuales cada sujeto interpretativo ejerce un poder sobre el tiempo. Ese poder es el de establecer una convergencia entre la historia de la práctica legal y los hechos ${ }^{7}$. Desde este punto de vista, el problema al que alude Supiot (2012) es esencialmente semiótico.

La construcción de un determinado referente de justicia, la huella de la que parte ese recorrido a lo pasado ausente, tiene situación en el rito judicial, donde lo que ya no es se presenta como algo actual: aquello que ha sido (en filosofía del derecho, denominado post res perditas). En palabras de Gernet (en Foucault, 2014: 95), “el único tiempo de referencia es el tiempo judicial".

Consideramos el discurso donde convergen las temporalidades del derecho y el hecho no ya en la inmanencia del signo saussureano (que supone que un hecho singular relatado remite necesariamente a una norma general), sino como "ese conjunto regular de hechos lingüísticos en determinado nivel, y polémicos y estratégicos en otro" (Foucault, 1996: 16). Saussure (1945) apostaba por una ciencia que estudiara la vida de los signos en el seno de la vida social, que nombró semiología: "nosotros la llamaremos Semiología (del griego sémeion, 'signo')” (Saussure, 1945: 43). Paul Ricoeur (2000) nos ofrece un camino alternativo, cuando rescata de las reflexiones aristotélicas sobre la memoria y el tiempo otra categoría, semèia (señales).

La semèia designa la inscripción depositada por un anillo en una lámina de cera. Al observar la marca, nos enfrentamos a la huella del impulso de la mano hacia la lámina. Lo ausente de la inscripción es su

\footnotetext{
${ }^{7}$ La recuperación del expediente judicial del caso Pierre Rivière para el análisis crítico plasmado en el conocido texto de Michel Foucault (1973) tematiza esta convergencia de los tiempos pasado y presente y pone de relieve los efectos de verdad de los discursos del campo judicial. El próximo subtítulo de este ensayo acude al análisis foucaultiano como un marco de referencia que permite encuadrar el fenómeno discursivo del campo jurídico.
} 
alteridad, su exterioridad constitutiva. La fuerza de la categoría reside en que sustituye la noción saussureana de signo por una que da cuenta del tiempo del sentido. El reconocimiento del sujeto en la verdad judicial que él mismo produce reconstruye una distancia temporal ${ }^{8}$ a partir de semèias producidas en el propio discurso.

\subsubsection{El relato de una memoria de sí como veridicción judicial}

Así, las condiciones de emergencia de la veridicción judicial, las complejas relaciones de fuerza entre los múltiples posicionamientos y el reenvío que una inscripción demostrativa produce a un pasado ausente son tres planos de un mismo problema semiótico: la argumentación que procede como un decir veraz del pasado. Decimos que es semiótico porque explora lo discursivo desde una crítica de la subsunción formal de hechos a normas, que se declara ubicada en la temporalidad del dogma (Supiot, 2012).

No exploramos aquí características inmutables de la discursividad jurídica ni su exterior no jurídico. Focalizamos, antes bien, las formas específicas en que emerge y opera el discurso que se adjudica la autorización jurídica en un momento dado.

En un sentido análogo, Foucault (2014 [2012]) llama la atención sobre su vocación historicista y declara su interés por la práctica de la veridicción judicial: "el problema no pasa por saber en qué condiciones ${ }^{910}$ será verdadero un enunciado (...), es determinar cómo pudo aparecer en la historia, y en qué condiciones, un modo de veridicción, un Wahrsagen" (Foucault, 2014 [2012]: 29). Paul Veyne (2010) asegura que el autor de

\footnotetext{
${ }^{8}$ Y, por lo tanto, en términos aristotélicos, reconstruye el carácter político de la construcción de la verdad judicial.

${ }^{9} \mathrm{El}$ autor, en el mismo texto, califica las condiciones del enunciado verdadero como aquellas formales o trascendentales condiciones que conforman un objeto filosófico que él evade. No deberíamos entender que, con esta mención, el autor hace referencia a las condiciones históricas y políticas del decir verídico, a las cuales, en definitiva, él dedica gran parte de su obra.
} 
La verdad y las formas jurídicas consideró la categoría nietzscheana Wahrsagen para producir "no una teoría lógica o filosófica de la verdad, sino una crítica empírica y casi sociológica de decir la verdad" (Veyne, 2010: 93).

Mónica Cabrera (2003) ofrece una reflexión sobre el papel de la parresía en la historia de constitución de la subjetividad moderna, formada en su vínculo con regímenes del decir verídico. Mediante la fórmula hermenéutica el sujeto, Foucault parte de la unidad formal e inmutable en que se había consagrado el sujeto cartesiano y, al igual que un texto o un dato cerrado, la abre a la interpretación. El sujeto en tanto texto a interpretar asegura la autora, se vuelve un "corpus en el que hay que hurgar para encontrar el sentido, cadáver parlante o por lo menos murmurante" (Cabrera, 2003: 23-24).

Sin embargo, con anterioridad al "último Foucault" que evoca Cabrera (2003), un texto de 1973 preanuncia el tránsito a la genealogía del sujeto. Junto a su equipo de investigación, publicó los documentos que rodean un caso de parricidio del siglo XIX: Moi, Pierre Rivière, ayant égorgé ma mère, ma soeur et mom frère. El cuerpo de Paul Rivière, que yacía ahorcado en la celda donde fue confinado en 1836, y el texto de sus memorias son también supuestas unidades formales, pero, a instancias de esta publicación, devinieron piezas que remiten a un complejo de técnicas de veridicción sobre el símismo y a las disputas al interior de ese complejo.

El libro construye una serie discursiva de archivo que tematiza el caso de un joven condenado a muerte por el asesinato de su madre, su hermana y uno de sus hermanos en noviembre de 1835, pero beneficiado luego con la conmutación por la pena de prisión perpetua. A la primera decisión siguieron los informes psiquiátricos que adjudicaron el hecho a un caso de monomanía homicida. La discusión sobre la inclusión de esta categoría en la administración de justicia penal es el signo de una pugna en el campo jurídico de la época: ¿qué lugar le cabría a la psiquiatría en el proceso de conformación de la subjetividad criminal? Los enunciados de esta serie — del juez, el procurador, el Ministro de Justicia, el médico rural, 
los testigos y los psiquiatras - combinan diferentes sistemas semióticos, "una batalla de discursos y a través de los discursos" (Foucault, 2009 [1973]: 18).

El conglomerado discursivo sobre el caso Rivière es un ejemplo de la interacción entre prácticas de veridicción que delimitan lo que puede y no puede categorizarse como subjetividad criminal en determinados momentos. La gubernamentalidad aplicada al campo judicial cobra forma en el concepto de obligación de verdad. El acusado debe adecuar su sí mismo al sujeto moral construido para él (Foucault, 2014 [2012]). Si las memorias de Pierre Rivière engañaron hasta a su propio autor, es porque en tanto decir veraz sobre el sí mismo aparece como el cumplimiento de una obligación en un determinado régimen de veridicción. Sus declaraciones escritas correspondieron, en Francia y en 1836, a las de un monomaníaco homicida.

"Rivière promete relatarnos por escrito lo que nos declaró de viva voz" (Foucault, 2009 [1973]), anuncia el oficial de justicia. "Diré la verdad", asiente Rivière. "Hasta ahora mantuve un sistema y un papel que no quiero aguantar por más tiempo. (...) es para sacar a mi padre de apuros, que hice lo que hice" (Foucault, 2009 [1973]: 45). Si las memorias del acusado se convirtieron en "pieza de convicción" (Foucault, 2009 [1973]: 60), como sostiene el acta de remisión del fiscal a la cámara de acusación, no es a instancias de un criterio de clasificación de lo verdadero y lo falso, sino en el marco de un conjunto de transformaciones de un régimen de veridicción. En un primer momento, su discurso conformó una prueba de su punibilidad. Sin embargo, a continuación, sería el índice de una circunstancia atenuante. Bajo el dominio naciente del concepto monomanía homicida, el mismo enunciado produce un relato de lo ocurrido que justifica la conmutación de la pena".

Este contraste se hace visible en los dos enunciados que transcribimos aquí. El primero, previo a la sentencia a pena de muerte, apareció en los Anales de Higiene Pública, y el segundo, posterior, en el dictamen conjunto de psiquiatras reconocidos de la época en Francia. 
(...) no es idiota ya que ha redactado una Memoria cargada de sentido; y finalmente, no es un demente, como podrá apreciarse a simple vista. Luego, Pierre Rivière no es un alienado (Foucault, 2009 [1973]: 165).

El relato de su vida escrita por Pierre Rivère demuestra una aberración profunda y constante de sus facultades intelectuales (...), la integridad de su memoria y el encadenamiento de ideas que este relato pone de manifiesto (...) varias veces lo hemos visto en las relaciones de maníacos y monomaníacos que escriben la historia de su enfermedad. Estos homicidios son únicamente debidos al delirio (...) (Foucault, 2009 [1973]: 193-194).

Si el discurso del acusado es una veridicción es debido a que responde a la medida de la interpelación que le ha sido dirigida sobre su sí mismo. La veracidad de su decir reside en que ofrece la dramatización de una subjetividad requerida por una singular maquinaria psiquiátricojudicial (Foucault, 2014 [2012]).

\subsubsection{El relato del derecho}

Destacar el carácter actuado de las escenas de veridicción que anteceden la decisión del juez equivale a reconocer en la verdad jurídica un objeto construido por el mismo posicionamiento que lo ostenta como un a priori. Sin embargo, como dijimos, el dogma jurídico es presentado por el texto legal con una temporalidad propia (Supiot, 2012). El efecto es una suerte de desdoblamiento del tiempo de la práctica jurídica, que Marí (2001) ha sabido señalar:

Entre el derecho positivo expresado en las leyes y el referente absoluto de la Ley atravesado por el inconsciente, existen lazos, 
que vinculan dos escenas: la escena visible de las normas jurídicas que regulan la conducta transparente de los hombres, y lo que Freud llamó la otra escena, anderes Schauspiel, ajena a su obrar consciente (Marí, 2009: 55).

El sujeto de la subsunción formal de hechos a normas se resiste a superponer la temporalidad del dogma al tiempo histórico. Sigue, en términos de Martyniuk (2009), la partitura y la cadencia de la adjudicación del juez inscrita en su sentencia. Sin embargo, tanto el acontecimiento del proceso judicial que interpreta esa partitura como la irrupción del objeto procesal se precipitan, ambos, en el tiempo histórico. Esta es la principal característica del acto de enunciación jurídica: instituye el pasado por derecho y, a la vez, lo dota de gravitación en el presente. "Es que el derecho", recuerda Martyniuk (2009), "emerge claramente como un dispositivo de control del tiempo" (75).

El objetivo de un análisis semiótico en esta dirección (Aniceto, 2017a, 2017b) es desplazar las categorías establecidas de lo justo del rasgo formal de punto de partida. Los enunciados de la adjudicación no forman consecuciones de anáforas que mantienen un referente existente previo, sino un acontecimiento de construcción estratégica del referente, o acto de referenciación.

\subsection{La analítica de la referenciación del relato judicial}

De lo dicho, se desprende la necesidad de explorar las posibilidades de una analítica de la referenciación para el abordaje de los relatos judiciales.

Nora Wolfzun (2009) y Bernard Jackson (1988), desde la filosofía del derecho y la semiótica jurídica respectivamente, establecen posicionamientos cercanos a la hipótesis de la doble interceptación de la referencia, de Van Roermund (1997). Roermund contribuyó a una teoría de la significación social del referente jurídico, en un contrapunto 
al paradigma del representacionismo. El autor formuló como hipótesis lo que Landowski et alii (1980) ya habían considerado al categorizar la doble isotopía del discurso jurídico: la modalidad específica del discurso jurídico, había asegurado, está dada en el hecho de que reenvía a la realidad del mundo que él mismo produce.

Traemos la hipótesis de la doble interceptación para subrayar el aporte de nuestra concepción de relato del derecho al diseño de un especial modo de abordaje semiótico del discurso jurídico. Roermund (1997), Landowski et alii (1980), Jackson (1988), Cover (2002) y Calvo González (1996) coincidirían en afirmar que derecho y relato son dos categorías tributarias de una concepción alternativa de chain novel. Nuestra perspectiva alberga una decisión teórica que avanza en esta dirección. Considera la historia de la práctica legal desde la posición del observador semiótico y no desde la del operador jurídico que la interpreta para tomar una decisión.

El Hércules de Dworkin, está preocupado por interpretar una historia con ocasión de indagar en los principios que fundamentan la norma para juzgar los hechos relatados. El observador semiótico, en cambio, se ocupa de elaborar una teoría sobre la producción histórica del sentido en el campo judicial. La diferencia decisiva es que la ocasión del observador semiótico es la de quien atribuye los posicionamientos sobre lo normativo y el pasado que emergen en las indagaciones del operador jurídico. Hércules, en Law's Empire, es el modelo del observador judicial que aborda el problema de la interpretación y la escritura integralista. El semiótico, es un observador de segundo orden que atribuye los efectos de sentido del abordaje del observador judicial.

Este posicionamiento de segundo orden parte de reconocer que, en el presente del duelo judicial, los relatos producen apuestas por formalizar institucionalmente el pasado que presentan como su referente previo. 


\subsubsection{El campo judicial, un campo político}

Raquel Taranilla García (2012) describe el enfoque que asumimos aquí como una tendencia escéptica posmoderna que descree de la capacidad referencial del lenguaje. "Ese cambio de paradigma provocó, necesariamente, que, en el ámbito del derecho, fuesen cuestionadas las teorías que aceptaban que la práctica de la prueba permite que los operadores jurídicos puedan aprehender la realidad externa" (Taranilla García, 2012: 47).

Más allá de sus denominaciones posibles, el enfoque construccionista es conjugado aquí con uno que atiende a su carácter agonístico. Con la aparición del discurso judicial, son desplegados posicionamientos argumentativos que asumen y trasladan la carga de la prueba, distintas estrategias de referenciación, y no precisamente en un proceso armónico de aplicación de reglas a hechos (Kennedy, 1991).

Analizar las regularidades y variaciones del discurso jurídico implica sustraer el análisis al régimen del Soberano-Ley (Foucault, 1998). Sustraerlo al mito fundador del destinador suplente "llamado a redecir el derecho" (Landowski et al, 1980: 100). Implica, en fin, sustituir el modelo jurídico de atribución de significados estables por un modelo estratégico de atribución de actos de significación contingentes.

2.3.1.1. El reparto de papeles y las apuestas narrativas del acto procesal

La perspectiva semiótica que proponemos reconoce en la aparición del storytelliig una función de referenciación de dominios de justicia. Desde singulares universos referenciales de lo justo, el relato prescribe normas sobre el deber ser de los hechos, que llamamos nomos históricos, y normas sobre el deber ser del campo adversativo donde el relato emerge, que llamamos nomos procesal o jurídico.

La práctica discursiva del relato judicial comporta una 
reconstrucción estratégica de acontecimientos del pasado, pero también y al mismo tiempo, la legislación de un modelo de acontecimiento justo, irreprochable. Modelo no-dicho en la legislación formal ni verbalizado en alegatos y sentencias, pero sancionado en los relatos que dan existencia procesal al hecho histórico. Si la descripción es también prescripción, no solo es al nivel de la formulación de una sentencia con efectos jurídicopenales, sino también al de la postulación del deber ser de la historia, de nomos históricos.

Ahora bien, si, como sostiene Landowski (1993), tanto el pasado reconstruido por el relato como el mismo conjunto enunciativo que esos relatos componen, el del discurso de adjudicación, son hechos, se hace necesario componer un par nocional que sume a la observación de nomos históricos, la de nomos procesales o jurídicos.

En un plano diacrónico de análisis, el relato de los hechos, además de remitir a una norma sobre la historia pasada, también reenvían a una sobre el buen funcionamiento del campo discursivo judicial y de los posicionamientos que lo conforman. En singulares contextos de interacción discursiva, la representación del discurso judicial emerge polémicamente como una palabra de conocimiento o una postura epistemológica (Carranza, 2007) que ofrece evidencias de un procedimiento judicial válido al tiempo que se presenta como la evidencia más inmediata.

Entonces, los relatos judiciales delimitan sus dos sedes tópicas (del latín sedes, el lugar fundante, habilitante) y simbólicas de enunciación: donde inscriben dominios de memoria, y donde categorizan el campo discursivo judicial jurídicamente preferible.

Sin embargo, lo evocado por una de las categorías, el nomos histórico, tiene puntos de contacto o segmentos superpuestos con lo evocados por la otra, el nomos jurídico. Todas las especificidades de una estrategia de enunciación judicial reverberan tanto en la inscripción de dominios de memoria como en la reconstrucción del acontecimiento judicial. 


\subsubsection{Los nomos histórico-procesales en el discurso judicial}

La definición teórica de las categorías analíticas que denominamos nomos histórico y procesal requiere, para su comprensión, exponer su funcionamiento en análisis concretos de enunciados judiciales efectivos. En un análisis de las últimas palabras de acusados por crímenes de lesa humanidad en juicios de Argentina, apliqué ese par categorial al abordaje de los relatos judiciales de estos actores legos. De conformidad con la hipótesis de la inversión simbólica de las tensiones formales entre legosprofesionales, partimos de asumir que el discurso de los acusados durante sus últimas palabras construye sujetos con pretensión de corrección jurídica.

Desde este punto de vista, trazamos los límites de un campo discursivo en el que incluimos a los sujetos de enunciación que emergen (en actuaciones verbales de profesionales y, en este caso, de legos) categorizando y recategorizando el pasado justiciable y el presente del juicio desde un posicionamiento equidistante y formalizador. La carencia de autorización formal o institucional de algunos actores del rito no impide al observador semiótico la tarea de reconocer en sus enunciados huellas de una formación discursiva jurídica. Aquí aludimos a las huellas de una estrategia común de normalización del propio relato, en un campo de relaciones de fuerza. Los enunciados de los ex militares acusados, en analogía con los de sus defensores, los fiscales y los jueces, aparecen como veridicciones que argumentan la necesidad jurídica de sus relatos.

Rodolfo Aníbal Campos era un ex militar argentino que cumplió un papel activo en la dirección del terror estatal durante la última dictadura en el país (1976-1983). En la causa donde fue acusado, y finalmente condenado a prisión perpetua, la imputación se refería a crímenes atroces cometidos contra un policía de la Provincia de Córdoba, Ricardo Fermín Albareda, por sus propios compañeros bajo la orden de Campos. Albareda fue secuestrado en la vía pública de la ciudad capital de Córdoba, trasladado a diversos centros clandestinos de desaparición y exterminio, y luego, 
asesinado por las fuerzas policiales cordobesas. Desde inicios de 1979, Campos se encontraba al mando de la Policía de Córdoba y coordinaba la represión policial en la provincia bajo el mando del Tercer Cuerpo de Ejército, presidido por Luciano B. Menéndez.

Este último fue otro de los acusados en el juicio de 2009 donde Campos enunciaría sus últimas palabras previas a la sentencia. De hecho, Menéndez precedió en el uso de la palabra a su ex subordinado ${ }^{10}$. El 11 de diciembre de 2009, antes de conocer la sentencia del tribunal, Rodolfo Campos formuló su última declaración.

\section{CAMPOS. UNA APUESTA NARRATIVA "ENTRE OTRAS"}

Buenos días, señor presidente. Le pido autorización para primero agradecer a los abogados defensores por el empeño puesto de manifiesto en la defensa de esta causa que es difícil porque... cosas que la razón no alcanza a comprender.

Desde el inicio de su declaración, el enunciado de Campos inscribe un nomos procesal que establece las condiciones de validez de los relatos $\mathrm{y}$, con arreglo a ese nomos, categoriza los posicionamientos del campo judicial:

[...] una verdad que no quiero que sea la única, ni pretendo ser el dueño de la verdad. Sí pretendo que si hay otras verdades, que no me confundan la mía. Pero además, con mayor énfasis, manifiesto que las otras verdades tengan los fundamentos que hacen a un desarrollo verdadero de los acontecimientos [...]

\footnotetext{
${ }^{10}$ Valdrá remitirse al estudio donde analizamos la escena de veridicción de Menéndez en este juicio y en otros dos, realizados antes y después en Córdoba (Aniceto, 2017a).
} 
"La verdadera base" (un relato entre otros) y "la verdadera conclusión" (una sentencia posible entre otras) constituyen el fundamento y el corolario del mismo dominio de memoria inscrito: el que reenvía a una historia no-relatada de la que, en efecto, ningún enunciador del campo discursivo ha sacado las conclusiones jurídicamente necesarias:

[...] Analizaremos los hechos. Veamos. Comencemos por el año 1970, seguiremos con el setenta y cinco y el del setenta y seis, y luego... del setenta y nueve, perdón ... y luego del setenta y nueve, abarcaremos 2006 y 2009 [...]

[...] En el setenta, compartiendo todo lo que ha dicho el señor general Menéndez, estábamos en una guerra declarada por el marxismo internacional [...]

El posicionamiento discursivo construido es el de un sujeto de un saber compartido por actores que, en el pasado, sufrían "una guerra declarada por el marxismo internacional" y, en el presente, tienen el derecho de comprender - “cosas que la razón no alcanza a comprender"-, en simetría con la obligación que se atribuye el yo-enunciador de hacer comprensible:

[...] Pero continuando con el análisis de esta causa, hablemos de la eliminación [...]. los acontecimientos que se siguieron obedecen todos a una situación de guerra que trataré de explicitar [...] Esto se da en una nación cuando empeña sus fuerzas armadas la detención legal de la guerra. Y cumplimos las órdenes legales de un gobierno legal [...].

La apuesta narrativa de Campos sanciona un nomos jurídico ligado a uno histórico. Sujeta la veracidad de un relato a la adscripción del enunciador a un orden legal guiado por la razón castrense para adjudicar hechos a normas. 
La dificultad de "la causa difícil de explicar" remite, desde este posicionamiento, a una carencia del campo judicial. El yo-enunciador argumenta, en definitiva, que no habían aparecido, hasta su intervención, relatos comprensibles. Lo susceptible de ser comprendido es lo que logra adjudicar normas a hechos. Entonces, la ruptura que se atribuye el yoenunciador se produce al anclar el relato en hechos que "obedecieran a una situación de guerra”. En las últimas palabras de Campos, hasta sus mismos defensores oficiales quedan incluidos en el conjunto de voces con esta carencia:

\section{[...] hemos escuchado a la doctora Evangelina Perez de} Mercado y al doctor Marcelo Arrieta en un esfuerzo que lo considero muy importante para rebatir los diferentes artículos, incisos y acusaciones [...].

"Los esfuerzos de los defensores" pueden ser importantes pero no cumplen con subsumir los hechos a la norma que regula "la situación de guerra". Entre otras cosas, porque no ostentan, conforme al nomos procesal o jurídico, adscripción castrense.

La apuesta narrativa de Campos se legitima como el discurso que saca a "la situación de guerra" de la penumbra a la que el campo judicial la había enviado. Construye, con esto, el posicionamiento de una voz que cumple la función pedagógica que "los esfuerzos" de otras voces, por más importantes que sean, no habían cumplido.

\subsection{La democracia y los peronistas del señor Perón}

Uno de los hechos que, bajo el ejido de este nomos jurídico, pertenece a este resto de hechos es el relatado como "la lucha" que dio a un general del Ejército, el "general Perón", "la victoria que esperaba disfrutar": 
[...] el general Perón, cuando regresa, en vez de encontrar el país con una alegría y con una paz consecuente con la victoria obtenida, porque asi sucedia, luchaban para que regrese, luchaban para tener elecciones y lo habian logrado en plenitud. En vez de recibir a nuestro general Perón, llega y lo primero que encuentra es una batalla en Ezeiza [...]

[...] ¿Alguien me puede explicar esa situación del general Perón que venía a disfrutar de un triunfo, de una victoria y que creía que esto... se iba a regir la ley, el orden y al contrario, más bombas, más asesinatos, más torturas, más secuestros y más todo? [...] [...] A través de esa batalla, ¿por qué lo relega al señor Cámpora, que estaba en el gobierno con el doctor Righi? [...]

[...] Y así va. Se llama a elecciones y las elecciones dan por resultado la presidencia de Perón [...].

Los efectos democráticos atribuidos a "una victoria militar" aparecen contrapuestos a los no-democráticos. Los segundos son los producidos por la degradación que el marxismo internacional produjo de "la lucha alegre por la democracia".

El discurso construye un pasado y le atribuye una estructura oposicional. Dos colectivos de identificación son opuestos por un acto de veridicción, que designa "la situación de guerra" como la norma que rige los hechos. Dos sujetos, "los peronistas del señor Perón” y "los peronistas del general Perón" son categorizados por un enunciador normativo que los subsume a esa norma.

Asignamos al relato de Campos la referencia a una pregunta que interpela los relatos de la acusación y de la sentencia inminente: ¿cómo justificar jurídicamente la degradación de "un general" victorioso del ejército que luchó por elecciones democráticas en "un señor" que instaló la guerra revolucionaria con sus colaboradores y seguidores? El reenvío a esta pregunta también construye una respuesta: hasta mi descargo, la degradación había sido, antes que justificada, ocultada. 
En primer lugar, la victoria militar de "un general" representa en la veridicción de Campos un punto de cierre de "la guerra revolucionaria instalada por el señor Perón". De esta forma, con arreglo al nomos histórico de "la situación de guerra", el general Perón triunfó frente al señor Perón. Y por lo tanto, en segundo lugar, las prácticas bélicas ("más bombas, más asesinatos, más torturas, más secuestros y más todo") posteriores a la victoria contradicen el principio que reconocemos como sustento del mismo nomos histórico: las victorias militares tienen efectos democráticos.

Tanto la pregunta por la degradación cuanto su respuesta reconstruyen estratégicamente el campo discursivo judicial, como uno donde antiguos usurpadores de la función judicial ("los peronistas del señor perón" que le dieron efectos no-democráticos a una victoria militar) son autorizados a encarnar el discurso jurídico. Entonces, emerge una categorización metaenunciativa: su propio discurso, rotulado como "un relato entre otros", deviene, en definitiva, una querella entre otras.

\subsection{Un sujeto "razonable" en un campo discursivo "difícil de entender"}

Sin embargo, el enunciado de Campos no se restringe a reconstruir acontecimientos y categorizarlos como necesarios para el arribo a una verdad jurídica, con toda la relevancia que tiene reconocer esta estrategia. Al mismo tiempo, y sobre todo, emerge como un punto de resistencia a las pautas predominantes de reconstrucción y categorización del campo discursivo donde aparece. El enunciado "mi verdad entre otras" aparece reenviando a esta idea, la de una simetría en la administración de la carga probatoria:

[...] Le pido autorización para primero agradecer a los abogados defensores por el empeño puesto de manifiesto en la defensa de esta causa que es difícil porque... cosas que la razón no alcanza a comprender [...]. 
Es "el juez" quien autoriza el orden legal castrense y son "los abogados defensores" quienes intentan comprender "una causa que es difícil". Las denominaciones de "la razón" y, por extensión, del dominio de lo razonable referencian un saber compartido capaz de identificar tres objetos: 1-la negación de asideros jurídicos a la querella, 2-la importancia del esfuerzo de los defensores, y 3-la importancia del esfuerzo del sujeto de la negación de los asideros.

Como dijimos, tomamos las últimas palabras de este ex militar perpetrador de crímenes de lesa humanidad como superficie de un argumento de la necesidad jurídica de sus relatos. La justificación del argumento por un relato procede como una mitología inmotivada. Opera en dos frentes, visiblemente en uno y solapadamente en otro. En el primero, intenta demostrar que su argumento es suficientemente razonable debido a su justificación en un relato necesario. En el segundo frente, como hemos observado, normaliza la continuidad que él mismo establece entre los actores y hechos relatados y el campo discursivo judicial.

Grüner (2005) lo asegura sin rodeos: "la práctica misma del rito es su propio "objeto": ella instaura la regla, o la serie de reglas — "el libreto" cuya letra debe seguirse minuciosamente - que impide la satisfacción plena del deseo" (Grüner, 2005: 74).

Asignamos a esta distinción el fin de organizar el análisis de las estrategias de referenciación que normalizan singulares dominios de memoria y que, al mismo tiempo, prescriben el modelo del discurso judicial. Sin embargo, es una distinción metodológica, no ontológica. En el despliegue efectivo de los relatos judiciales, no existe per se la distancia abstracta abierta entre nuestras categorías, entre unos y otros lugares normativos autohabilitantes que denominamos nomos históricos y jurídicos. 


\section{CONCLUSIONES}

Una mirada sociosemiótica se centra en la práctica de autojustificación. Autojustificarse implica no solo demostrar la cohesión interna de un silogismo, sino también, por medio de los relatos, dar por colmadas las exigencias externas, no exclusivamente jurídicas sino del discurso social, de justificación del propio argumento.

Campos inscribe un yo-enunciador que antepone una norma castrense para concebir el pasado. Conforma, en paráfrasis de Robert Cover (2002), un orden legal paideico o una gramática organizadora otra. El corpus normativo simbólico del que forman parte los nomos históricos $y$ procesales es una combinación para crear principios y hacerlos cuadrar en la reconstrucción del pasado y categorizar su propio posicionamiento en el rito judicial.

En conclusión, sostenemos que los roles procesales formales solo pueden abordarse en su dramatización por el observador semiótico que atribuye la semiosis del discurso judicial como semiosis prescriptiva, y no solo prescripta.

Nuestro planteamiento completo gravita en torno a un eje tópico específico: el carácter estratégico de la enunciación judicial, que conduce a la construcción de sujetos terceros equidistantes, y a la de un delimitado universo referencial de lo justo que esos sujetos argumentan encarnar.

Aquí se hace necesario explicitar lo que entendemos por construcción de un referente de lo justo y la relación que le asignamos con la práctica de la veridicción, desde una perspectiva foucaultiana. Debemos, en otras palabras, precisar las implicancias de adoptar - como lo hacemos aquí- una concepción relacional de las nociones jurisdicción y veridicción.

Partimos de un postulado que condensa una matriz explicativa y que seguidamente desarrollaremos: toda veridicción, en el combate entre gramáticas jurídicas que avanza hacia el ajuste narrativo del juez, dramatiza una jurisdicción, cita normas al mismo tiempo que las construye. 
Como puede notarse, nuestra afirmación retoma las categorías foucaultianas jurisdicción y veridicción como dos designaciones del carácter dramático, escénico, del discurso producido en los ritos judiciales. Y es, entonces, desde la semiótica jurídica crítica que reponemos la concepción del lazo entre veridicción y jurisdicción. El abordaje del discurso judicial como un acto que dramatiza la norma como forma de darle existencia procesal y actualidad en un rito es conducido por el interés en describir la contingencia de las audiencias judiciales. Estos eventos, preanunciados en reglas procedimentales pero portadores de una diferencia inédita constituyen los contextos de producción de una verdad sobre lo justo, que se presenta como la verdad sobre lo justo.

Sin embargo, Foucault (1996 [1978]; 2014 [2012]) no consagra la relación que establece entre veridicción y jurisdicción al restablecimiento de una ley natural sobre las prácticas judiciales. Al contrario, recorre la historia que ha consolidado esa relación y ha llevado a postular que "la verdad depende de la jurisdicción de un sujeto capaz de distinguir lo ilusorio y lo falso de lo real y lo verdadero" (Brion y Harcourt, 2014: 13).

Entonces, asumimos una perspectiva foucaulteana para sostener, que las prácticas judiciales escenifican discursos verdaderos producidos en relación con lo que hay que saber (práctica de la veridicción) y revalidan programas de conducta que vinculan a los sujetos con lo que hay que hacer (práctica de la jurisdicción) (Foucault, 1973).

En definitiva, analizar enunciados en su acto de decir lo verdadero, ligado al decir lo justo, nos permite reconstruir sus efectos de verdad en el interdiscurso donde emergen y, por lo tanto, las gramáticas de juridicidad que pugnan por imponer a ese interdiscurso.

La escena judicial es el espacio de una compleja mise-en-scène, donde un enunciador profesional, argumenta la necesidad jurídica de su palabra. En estos límites, emplazados sobre el terreno del rito en curso, en realización escénica, se desarrolla el drama judicial donde no podemos comprender los efectos del decir lo que es justo, sin considerar la liturgia donde se jura decir lo que es verdadero. 
La visión apriorística y correspondentista de la verdad jurídica, como la que promueve el derecho positivo, no entraña una concepción inocente sobre la adjudicación, sino una concepción (y un esquema operatorio) que apunta a sostener una verdad mediante sus iteraciones. No es la verdad jurídica la que se impone desde el exterior del marco de enunciación para formular un ajuste narrativo con efectos penales. Es, en cambio, una verdad históricamente construida en el seno de diversas escenas judiciales sobre los hechos judicialmente reprochables. Escenas no estrictamente tribunalicias pero sí estrictamente políticas, a lo largo de un extenso proceso de producción de sentido.

La estrategia argumentativa de los relatos judiciales solo puede ser reconocida a condición de asumir el discurso de la sentencia, como el corolario de una relacion de fuerzas entre regímenes narrativos, en la que todo enunciado se corresponde a una apuesta narrativa.

\section{REFERENCIAS BIBLIOGRÁFICAS}

ALEXY, R. (2011). A Theory of legal argumentation. The theory de rational dicourse as theory of legal justification. Oxford/NY: Oxford Universidad Press.

ANICETO, P. (2016). "La superficie de emergencia del discurso jurídico y los debates de la semiótica jurídica". Semióticas: Miradas, recorridos y nuevos objetos de conocimiento. X Congreso Argentino y V Congreso Internacional de Semiótica. Santa Fe-Paraná. (2017a). "La construcción estratégica de la verdad en 'las últimas palabras' en juicios por crímenes de lesa humanidad". Discurso \& Sociedad 11.2, 323-354 (también en http://www.dissoc.org/ ediciones/v11n02/DS11(2)Aniceto.pdf [02/03/2018]).

(2017b). Las apuestas narrativas de las últimas palabras. El agon narrativo y los performances de acusados exmilitares en juicios 
por crímenes de lesa humanidad, en tribunales de Córdoba, entre 2008 y 2010. Tesis doctoral con mención en Semiótica. Facultad de Ciencias Sociales y Facultad de Filosofía y Humanidades de la Universidad Nacional de Córdoba (Argentina).

(2017c). "Una reflexión sobre el carácter agonístico de la práctica de jurisdicción. La construcción de ámbitos de justicia”. Nómadas $53,1-18$.

ASSEFF, L. (2003). Argumentación jurídica y semiosis social. Rosario: Editorial Juris.

BERTRAND, D. (2015). "Los regímenes de inmanencia, entre narratología y narratividad". Tópicos del Seminario 33, 163-188.

BIXIO, B. (2016). "Metodología cualitativa de análisis del discurso jurídico". En Metodología de la investigación jurídica: propuestas contemporáneas, G. Lariguet (comp.), 239-249. Córdoba: Brujas.

BALKIN, J.(1991). “The promise of Legal Semiotics". Faculty Scholarship Series 278, 1831-1852 (también en http://digitalcommons.law. yale.edu/cgi/viewcontent.cgi? article $=1277 \&$ context $=f_{\text {sS_papers }}$ [02/03/2018]).

CABRERA, M. (2003). "El último Sócrates de Foucault". En El último Foucault, T. Abraham (ed.), 17-38. Buenos Aires: Sudamericana.

CALVO GONZÁLEZ, J. (1996). Derecho y narración. Materiales para una teoría y crítica narrativista del Derecho. Barcelona: Editorial Ariel.

(2011). "Hechos como argumentos. Teoría narrativista y argumentación jurídica". En Tópica, retórica y dialéctica en la jurisprudencia: estudios en homenaje a Francisco Puy. Homenaxes, M. M. Otero Parga (ed.), 111-120. Santiago de Compostela, Galicia: Universidade de Santiago de Compostela.

CARRANZA, I. E. (2007). "La construcción de la evidencia". En Los estudios del discurso. Nuevos aportes desde la investigación en la Argentina. P. Vallejos Llobet (coord.), 17-36. Bahía Blanca: Editorial de la Universidad Nacional del Sur. 
CORREAS, O. (2005). Crítica de la ideología jurídica. Ensayo sociosemiológico. México: Ediciones Coyoacán.

COVER, R. (2002). Derecho, narración y violencia. Poder constructivo y poder destructivo en la interpretación judicial. Barcelona: Gedisa.

DE ÍPOLA, E. (2005). La bemba. Acerca del rumor carcelario. Buenos Aires: Siglo XXI.

DE SOUSA SANTOS, B. (2009). "Estado y el derecho en transición posmoderna: para un nuevo sentido común sobre el poder y el derecho". En Desde otra mirada. Textos de Teoría Crítica del Derecho, Ch. Courtis (ed.), 449-480. Buenos Aires: Eudeba.

DWORKIN, R. (1985). Law's Empire. Cambridge / London: The Belknap Press of Harvard University Press.

FOUCAULT, M. (2014 [2012]). Obrar mal, decir la verdad. La función de la confesión en la justicia. Buenos Aires: Siglo XXI. (2009 [1973]). Yo, Pierre Rivière, habiendo degollado a mi madre, a mi hermana y a mi hermano... Un caso de parricidio del siglo XIX. Barcelona: Tusquets Editores.

(1996 [1978]). La verdad y las formas jurídicas. Barcelona: Gedisa.

FROW, J. (1995). "A note on legal semiotics". Social Semiotics 5.2, 183-189 (también en https://minerva-access.unimelb.edu.au/ bitstream/handle/11343/34476/67029_00002649_01_Frow041. pdf? sequence $=1 \&$ is Allowed $=y[02 / 03 / 2018])$.

FRUTOS, S. (2007). “Afiliaciones en la transgresión. Significados en torno a la ley y las prácticas penales". Dossier de Estudios Semióticos de La Trama de la Comunicación 12, 191-205.

GRÜNER, E. (2005). La cosa política o el acecho de lo real. Barcelona: Paidós.

GUARDIA, L. (2013). “Sobre logos jurídico y democracia en el pensamiento político posfundacional”. Revista Filosofía del Derecho 3, 4968 (también en http://www.saij.gob.ar/doctrina/dacf140128-guardia-sobre_logos_juridico_democracia.htm [02/03/2018]).

JACKSON, B. S. (1988). Law, Fact and Narrative Coherence. Merceyside: 
Deborah Charles Publications.

KOZICKI, E. (2004). Hamlet, el padre y la ley. Buenos Aires: Gorla.

KRISTEVA, J. (1981). Semiótica I. [1969, 1. a edición]. Madrid: Editorial Fundamentos.

LANDOWSKI, E. (1993). La sociedad figurada. Ensayos de sociosemiótica. México: Fondo de Cultura Económica.

LANDOWSKI, E. et alii (1980). "Análisis semiótico de un discurso jurídico. La ley comercial sobre las sociedades y los grupos de sociedades". [1976, 1. a edición]. En A. J. Greimas, 87-129. Madrid: Fragua.

LEGENDRE, P. et alii (1982). El discurso jurídico. Perspectiva psicoanalítica y otros abordajes epistemológicos. Buenos Aires: Hachette.

MARÍ, E. (1982). “'Moi, Pierre Rivière...' y el mito de la uniformidad semántica en las ciencias sociales y jurídicas". En El discurso jurídico. Perspectiva psicoanalitica y otros abordajes epistemológicos, P. Legendre et alii, 53-82. Buenos Aires: Hachette. (2001). El Banquete de Platón: el eros, el vino, los discursos. Buenos Aires: Biblos.

(2009). "Diferentes modos de acceso a la articulación entre derecho y psicoanálisis". En Desde otra mirada. Textos de teoría crítica del Derecho, Ch. Courtis (comp.), 39-58. Buenos Aires: Eudeba.

MARTYNIUK, C. (2009). "Sobre la narración hermenéutica de la normatividad: tesis sobre la hermenéutica, la novela del derecho y la retórica". En Desde otra mirada. Textos de teoría crítica del Derecho, Ch. Courtis (comp.), 59-80. Buenos Aires: Eudeba.

NARVAJA DE ARNOUX, E. (2009). Análisis del discurso. Modos de abordar materiales de archivo. Buenos Aires: Santiago Arcos editor.

RICOEUR, P. (2004). Tiempo y narración I. Configuración del tiempo en el relato histórico. [1985, 1. a edición]. Buenos Aires: Siglo XXI.

SUPIOT, A. (2012). Homo juridicus. Ensayo sobre la función 
antropológica del derecho. [2005, 1. a edición]. Buenos Aires: Siglo XXI (Colección Derecho y Política).

TARANILLA GARCÍA, R. (2012). La justicia narrante. Un estudio sobre el discurso de los hechos en el proceso penal. Madrid: Editorial Aranzadi.

VAN ROERMUND, G. (1997). Derecho, relato y realidad. Madrid: Tecnos.

VERÓN, E. (1987). La semiosis social. Fragmentos de una teoría de la discursividad. Barcelona: Gedisa.

VEYNE, P. (2010). Foucault: His Thought, His Character. London: Polity Press.

(2013). La semiosis social, 2. Ideas, momentos, interpretantes. Buenos Aires: Paidós.

WOLFZUN, N. (2009). "Las marcas del vacío en el discurso social". En Desde otra mirada. Textos de teoría crítica del Derecho, Ch. Courtis (comp.), 235-242. Buenos Aires: Eudeba.

Recibido el 2 de marzo de 2018.

Aceptado el 18 de julio de 2018. 